Jumal Sosialisasi

Jurnal Hasil Pemikiran, Penelitian, dan Pengembangan

Keilmuan Sosiologi Pendidikan

Vol 8, Nomor 1, Maret 2021

\title{
PERAN KOMITE PEMANTAU LEGISLATIF (KOPEL) DALAM MENDORONG KINERJA LEGISLASI DPRD KOTA MAKASSAR
}

\author{
Andi Aco Agus ${ }^{1}$, Randiawan ${ }^{2}$ \\ ${ }^{1,2}$ Program Studi Pendidikan Pancasila dan Kewarganegaraan, Fakultas Ilmu Sosial, \\ Universitas Negeri Makkassar \\ andi.aco.agus@unm.ac.id ${ }^{1}$,randy.tomalinrung98@gmail.com ${ }^{2}$
}

\begin{abstract}
ABSTRAK
Penelitian ini bertujuan untuk mengetahui (1) Untuk mengetahui dan memperoleh data empiris peran komite pemantau legislatif dalam mendorong kinerja legislasi DPRD Kota Makassar. (2) Mengetahui dan menilai tingkat keberhasilan komite pemantau legislatif dalam mendorong kinerja legislasi DPRD Kota Makassar. Jenis penelitian ini adalah kualitatif dengan fokus pada fenomena, kejadian, perilaku. sikap, khusus dalam penelitian sosial. Teknik pengumpulan data yang digunanakan yaitu observasi, wawancara dan dokumentasi, yang digunakan untuk memperoleh data secara konkret yang berkaitan dengan permasalahan dalam penelitian ini. Data yang diperoleh dalam penelitian ini di analisis dengan analisis deskriptif kualitatif. Hasil dari penelitian menunjukkan bahwa: (1). Peran komite pemantau legislatif (KOPEL) dalam mendorong kinerja legislasi DPRD Kota Makassar : a) Advokasi kebijakan pemerintah daerah meliputi: Sekolah parlemen KOPEL Indonesia, Workshop, Training Legal drafting. b) Riset dan pengembangan kinerja DPRD Kota Makassar meliputi Publik hearing, Menyiapkan draf analisis, rapat dengar pendapat. c) Pendampingan masyarakat sipil. (2). Tingkat keberhasilan komite pemantau legislatif (KOPEL) dalam mendorong kinerja legislasi DPRD Kota Makassar diantaranya: a) Peningkatan pemahaman dalam menyusun peraturan, b) Peningkatan transparansi kapasitas kinerja sekretariat DPRD Kota Makassar, c) Memperkuat transparansi dukungan penerimaan aspirasi masyarakat, d) Memperkuat transparansi dengan fasilitas e-parlement kopel Sulawesi, e) Membangun keahlian legal drafting.
\end{abstract}

Kata kunci: Peran KOPEL, Kinerja Legislasi, Kota Makassar.

\begin{abstract}
This study aims to determine (1) To find out and obtain empirical data on the role of the legislative monitoring committee in encouraging the legislative performance of the Makassar City DPRD. (2) Knowing and assessing the success rate of the legislative monitoring committee in encouraging the legislative performance of the Makassar City DPRD. This type of research is qualitative with a focus on phenomena, incidents, and behaviors. attitudes, specifically in social research. Data collection techniques used were observation, interviews and documentation, which were used to obtain concrete data related to the problems in this study. The data obtained in this study were analyzed with qualitative descriptive analysis. The results of the study indicate that: (1). The role of the legislative monitoring committee (KOPEL) in encouraging the legislative performance of the Makassar City DPRD: a) Advocacy for local government policies including: KOPEL Indonesia parliamentary school, Workshop, Legal drafting training. b) Research and development of the performance of the Makassar City DPRD including public hearings, preparing draft analyzes, and hearings. c) Assistance for civil society. (2). The success rate of the legislative monitoring committee (KOPEL) in encouraging the legislative performance of the Makassar City DPRD include: a) Increasing understanding in drafting regulations, b) Increasing the transparency of the performance capacity of the Makassar City DPRD secretariat, c) Strengthening transparency in supporting the acceptance of public aspirations, d) Strengthening transparency by Sulawesi coupling e-parlement facility, e) Building legal drafting expertise.
\end{abstract}

Keywords: Role of KOPEL, Legislation Performance, Kota Makassar. 


\section{PENDAHULUAN}

Konsep civil society karakteristik Lembaga Swadaya Masyarakat (LSM) yang bercirikan mandiri dan tidak menguntungkan diri pada bantuan pemerintah, dipandang dapat memainkan peran yang sangat penting dalam proses memperkuat gerakan demokrasi melalui perannya dalam pemberdayaan civil society yang dilakukan melalui berbagai aktivitas pendampingan, pembelaan, dan penyadaran.

Lembaga Swadaya Masyarakat (LSM) merupakan salah satu bagian masyarakat sipil yang masih bersikap kritis dan bersuara lantang terhadap berbagai bentuk perilaku Korupsi, Kolusi, dan Nepotisme (KKN) dan termasuk menyangkut masalah kinerja legislatif. Anggota Legislatif Kota Makassar selama ini menjadi sorotan publik seperti halnya yang sering dilakukan oleh Lembaga swadaya masyarakat salah satunya adalah Lembaga Komite Pemantau Legislatif (KOPEL).

Komite Pemantau Legislatif Indonesia atau disingkat KOPEL Indonesia, KOPEL merupakan lembaga Non Government Organization (NGO). Bertujuan untuk mewujudkan terlaksananya sistem demokrasi dalam tatanan kehidupan bernegara dengan fokus pada pengawasan dan evaluasi kinerja wakil rakyat (Kusuma, 2019). Untuk mencapai tujuan tersebut, Komite Pemantau Legislatif (KOPEL) Indonesia memfokuskan programprogramnya dalam melakukan pengawasan kinerja legislatif sebagai lembaga rakyat, memberikan penguatan terhadap lembaga partai politik, memberikan pendidikan politik yang kritis bagi masyarakat serta melakukan pengawasan terhadap kebijakan peraturan daerah, Anggaran Pendapatan Belanja Daerah (APBD).

Lembaga Suprastruktur Dewan Perwakilan Rakyat (DPR) tentunya memiliki fungsi yang tercantum dalam Pasal 20A ayat (1) Undang-Undang Dasar Negara Republik Indonesia Tahun 1945 "Dewan Perwakilan Rakyat memiliki fungsi: Legislasi, Anggaran, dan Pengawasan". Fungsi legislasi merupakan kekuasaan untuk membentuk undangundang yang dibahas dengan presiden untuk mendapat persetujuan bersama, fungsi anggaran adalah kekuasaan untuk menyusun dan menetapkan Anggaran Pendapatan Belanja Negara (APBN), dan fungsi pengawasan yaitu melakukan pengawasan terhadap pelaksanaan undang-undang dasar Negara republik Indonesia tahun 1945, undang-undang, dan peraturan pelaksanaannya.

Dewan Perwakilan Rakyat tidak hanya mempunyai fungsi seperti pada pasal 20A ayat (1) Undang-Undang Dasar Negara Republik Indonesia Tahun 1945, tetapi DPR mempunyai tugas yang dijelaskan pada Pasal 72 Undang-undang Republik Indonesia nomor 17 tahun 2014 tentang Majelis Permusyawaratan Rakyat, Dewan Perwakilan Rakyat, Dewan Perwakilan Daerah, dan Dewan Perwakilan Rakyat Daerah. (Lembar Negara Republik Indonesia Tahun 2014 Nomor 5568) DPR Bertugas: a. menyusun, membahas, menetapkan, dan menyebarluaskan program legislasi nasional; b. menyusun, membahas, dan menyebarluaskan rancangan undang-undang; c. menerima rancangan undang-undang yang diajukan oleh DPD berkaitan dengan otonomi daerah, hubungan pusat dan daerah, pembentukan dan pemekaran serta penggabungan daerah, pengelolaan sumber daya alam dan sumber daya ekonomi lainnya, serta yang berkaitan dengan pertimbagan keuangan pusat dan daerah; d. melakukan pengawasan terhadap pelaksanaan undang-undang, APBN, dan kebijakan pemerintah; e. membahas dan menindaklanjuti hasil pemeriksaan atas pengelolaan dan tanggungjawab keuangan negara yang disampaikan oleh BPK; f. memberikan persetujuan terhadap pemindahtanganan asset negara yang menjadi kewenangannya berdasarkan ketentuan peraturan perundang-undangan dan terhadap perjanjian yang berakibat luas dan mendasar bagi kehidupan rakyat yang terkait dengan 
beban keuangan negara; g. menyerap, menghimpun, menampung, dan menindaklanjuti aspirasi masyarakat; dan h. melaksanakan tugas lain yang diatur dalam undang-undang.

Lembaga Perwakilan Rakyat pada tingkat daerah disebut Dewan Perwakilan Rakyat Daerah (DPRD). Pasal 315 Undang-undang Republik Indonesia nomor 17 Tahun 2014 tentang Majelis Permusyawaratan Rakyat, Dewan Perwakilan Rakyat, Dewan Perwakilan Daerah, dan Dewan Perwakilan Rakyat Daerah. (Lembaran Negara Republik Indonesia Tahun 2014 Nomor 5568) "DPRD provinsi/Kab/Kota merupakan lembaga perwakilan rakyat daerah yang berkedudukan sebagai unsur penyelenggara pemerintahan daerah provinsi/kab/kota". Salah satu tugas dan wewenang DPRD tercantum pada Pasal 42 ayat (1) poin a dan b Undang-undang Republik Indonesia nomor 12 tahun 2008 tentang Pemerintah Daerah (Lembaran Negara Republik Indonesia tahun 2008 nomor 59) poin a "DPRD mempunyai tugas dan wewenang membentuk Perda yang dibahas dengan kepala daerah untuk mendapatkan persetujuan bersama". Dijalankan dalam kerangka representasi rakyat di Provinsi dan Kab/Kota. Poin b "DPRD mempunyai tugas dan wewenang membahas dan menyetujui rancangan Perda tentang APBD bersama dengan kepala daerah".

Konstruksi ketentuan dalam Undang-Undang Dasar Negara Republik Indonesia Tahun 1945 merupakan hasil amandemen konstitusi yang memperkuat kembali kekuasaan pembentukan undang-undang yang kini berada di DPR sebagai lembaga legislatif yang sesungguhnya (Tutik \& SH, 2016). Posisi yang demikian inilah, maka organ pembentuk, tata cara, dan proses pembentukan peraturan perundang-undangan menjadi titik sentral dari pembangunan sistem hukum nasional.

Legislasi daerah adalah instrument perencanaan program termasuk adalah penyusunan Rancangan Peraturan Daerah (RAPERDA) (Danusastro, 2016). Proses penyusunan RAPERDA salah satunya melalui jalur inisiatif pemerintah daerah sebuah perancangan masuk ke DPRD dari pemerintah yang kemudian dibahas dirapat dewan di analisis bersama dengan anggota DPRD untuk mendapat persetujuan bersama pemerintah (Ulhaq, 2021).

\section{METODE PENELITIAN}

Jenis penelitian yang digunakan dalam penelitian ini yaitu deskriptif kualitatif dengan pendekatan deskriptif. Pendekatan deskriptif dalam penelitian ini bertujuan untuk fokus pada fenomena, kejadian, perilaku, sikap menggambarkan secara sistematis dan akurat mengenai fakta-fakta. Penelitian ini dilakukan untuk mendapatkan gambaran umum mengenai "Peran Komite Pemantau Legislatif (KOPEL)". Lokasi penelitian ini dilaksanakan di Kantor Pusat KOPEL, Kota Makassar.

Teknik pengumpulan data yang digunakan yaitu observasi, wawancara dan dokumentasi. Dengan menggunakan teknik triangulasi sumber dalam pengujian kredibilitas pengecekan data.

\section{HASIL PENELITIAN DAN PEMBAHASAN}

Negara demokrasi merupakan konsep yang diimplementasikan di indonesia, melalui tata pemerintahan yang melibatkan masyarakat sehingga menyentuh setiap kalangan atau lapisan masyarakat (Suharto, 2005).

Makna kedaulatan rakyat dalam negara merupakan kedaulatan tertinggi berada dalam keputusan bersama rakyat, sebagai dasar hidup bermasyarakat dan bernegara 
mengandung pengertian bahwa rakyatlah yang memberikan ketentuan dalam masalahmasalah mengenai kehidupannya termasuk dalam menilai kebijakan negara. Kebijakan tersebut akan menentukan kehidupan rakyat, bahwa negara yang menganut sistem demokrasi adalah negara yang diselenggarakan berdasarkan kehendak dan kemauan rakyat. Maka hakikat demokrasi sebagai suatu sistem bermasyarakat dan bernegara serta pemerintahan memberikan penekanan pada keberadaan kekuasaan di tangan rakyat baik dalam penyelenggaraan negara maupun pemerintahan.

Pemerintahan oleh rakyat, berarti bahwa suatu pemerintahan menjalankan kekuasaan atas nama rakyat bukan atas dorongan diri dan keinginannya sendiri. Selain itu juga mengandung pengertian bahwa dalam menjalankan kekuasaannya, pemerintahan dalam pengawasan rakyat. Pengawasan rakyat dapat dilakukan secara langsung oleh rakyat maupun tidak langsung melalui perwakilan di parlemen (DPR, DPRD) (Kartini, 2017).

Pertama kali yang tampak dalam kelembagaan masyarakat sipil ialah lembaga rakyat. Lembaga rakyat merupakan tempat berkumpul dan bertemunya rakyat untuk membicarakan, menyampaikan, dan mengajukan protes jika sesuatu bertentangan dengan aspirasinya. Rakyat dengan inisiatifnya sendiri berkumpul sesuai dengan kesamaan tujuan tertentu (Setiadi \& Kolip, 2013).

Infrastruktur merupakan pusat kekuasaan politik rakyat, kekuasaan politik rakyat disektor infrastruktur (Bangunan bawah) terdapat pada elemen-elemen organisasi sosial, tokoh politik, tokoh masyarakat, alat komunikasi politik, dan terutama organisasi politik atau partai politik (Buchari, 2014). Infrastruktur politik juga dapat saja berbentuk perkumpulan buruh, perkumpulan petani, perkumpulan nelayan, perkumpulan pedagang, perkumpulan pemuda, perkumpulan karang taruna, bahkan organisasi kemasyarakatan lainnya yang menjadi elite power dalam politik kenegaraan (Maksum, 2020).

Organisasi non pemerintah mencakup semua organisasi masyarakat yang berada diluar struktur dan jalur formal pemerintah dan tidak dibentuk oleh birokrasi pemerintah. Lembaga Swadaya Masyarakat (LSM) hanya membatasi aktivitasnya untuk memperoleh kepercayaan masyarakat dan pemerintahannya sendiri (Firdaus, n.d.). Lembaga swadaya masyarakat mengidentifikasikan dirinya sebagai organisasi Nonprofit yang bukan pemerintah dan berdiri di atas landasan pemberdayaan kepada masyarakat (Rahmanurrasjid, 2008). Salah satu fungsi lembaga swadaya masyarakat adalah Mengontrol dan mengawasi kebijakan pemerintah baik dalam pemerintahan eksekutif maupun legislatif yang menjadi kedaulatan rakyat sebagai pemegang kekuasaan tertinggi (Haris, 2005).

Sebagai wujud partisipasi masyarakat maka para jurnalis dan akademisi membentuk salah satu Lembaga Swadaya Masyarakat yang disebut Komite Pemantau Legislatif (KOPEL). Komite Pemantau Legislatif bertujuan untuk mewujudkan terlaksananya sistem demokrasi dalam tatanan kehidupan bernegara dengan fokus pada pengawasan dan evaluasi kinerja wakil rakyat (Tiran, 2016).

\section{Peran Komite Pemantau Legislatif (Kopel) Dalam Mendorong Kinerja Legislasi Dprd Kota Makassar}

Dari hasil penelitian ini diketahui bahwa peran komite pemantau legislatif dalam mendorong kinerja legislasi DPRD Kota Makassar. KOPEL merupakan salah satu lembaga swadaya masyarakat (LSM) yang berperan dalam kerja-kerja pemantauan Melaksanakan pengawasan terhadap kinerja anggota DPRD sebagai wakil rakyat dan melaksanakan evaluasi terhadap hasil kinerja anggota DPRD. 
Jumal Sosialisasi

Jurnal Hasil Pemikiran, Penelitian, dan Pengembangan

Keilmuan Sosiologi Pendidiikan

Vol 8, Nomor 1, Maret 2021

\section{a. Advokasi Kebijakan Pemerintahan Daerah}

Melakukan advokasi terhadap kebijakan pemerintah daerah. Kebijakan pemerintah daerah yang dalam prosesnya akan dinilai oleh DPRD melalui tiga fungsinya yakni pengawasan, keuangan dan Pembentukan Perda. KOPEL dalam hal ini akan memberikan masukan kepada anggota DPRD terhadap kebijakan pemerintah daerah dengan melihat pada aspek partisipasi, akses, kontrol dan penerima manfaat dari sebuah kebijakan pembangunan yang dilaksanakan oleh pemerintah daerah.

KOPEL berperan untuk membantu DPRD memberikan pemahaman terhadap kebijakan pemerintah daerah, baik dari sisi anggaran, manfaat dan dampak yang ditimbulkan atas kebijakan tersebut bagi kemajuan pembangunan maupun manfaat yang luas bagi masyarakat (Permana, 2018).

1. Sekolah Parlemen KOPEL Indonesia), SPEKSI sebagai badan khusus/lembaga otonom bertujuan untuk meningkatkan kapasitas anggota DPRD mengenai keparlemenan baik dalam penyusunan peraturan, pengawasan, dan penganggaran. Sasaran dari SPEKSI ini adalah masyarakat sipil, anggota partai politik, pemerintah, dan individu anggota DPRD.

2. WORKSHOP ini sebagai pelatihan khusus untuk masyarakat sipil bagaimana menilai kinerja pemerintah dan DPRD. Orientasinya adalah masyarakat serta mahasiswa.

3. Pelatihan legal drafting ini berfokus pada calon anggota DPRD sebagai bekal dalam menyusun peraturan jika terpilih menjadi anggota DPRD. Orientasinya tidak lain adalah skill dan pengetahuan merancang dan menyusun produk peraturan.

\section{b. Riset dan Pengembangan Kinerja DPRD Kota Makassar}

KOPEL melakukan serangkaian penelitian/riset untuk untuk kepentingan lembaga. Melalui riset, KOPEL terbantu untuk melakukan advokasi kebijakan kepada pemerintah daerah dan pihak-pihak lain yang terkait dengan advokasi kebijakan yang sedang dilakukan. Sehingga hasil-hasil advokasi semuanya berbasis data yang dapat dipertanggung jawabkan keabsahannya. Oleh karena itu, riset yang dilakukan KOPEL dijadikan sebagai alat advokasi yang memudahkan setiap personil lembaga yang tersebar dalam setiap divisi dapat melakukan kerja-kerja organisasi secara baik, teratur, dan bertanggung jawab.

1. Hearing, bersama anggota DPRD membahas rancangan peraturan yang akan dibahas pada rapat paripurna DPRD atau disebut kopel berdiskusi.

2. KOPEL membuat draf analisis, peraturan untuk ditawarkan kepada DPRD dan sekaligus menjadi acuan dalam menyusun peraturan yang akan dibahas dalam rapat DPRD.

3. Rapat dengar pendapat (RDP), Memberikan masukan dan saran kepada anggota DPRD terhadap draft rancangan peraturan yang akan dibahas melalui draft analisis dari KOPEL. DPRD mendengarkan apa yang menjadi masukan dan usulan KOPEL.

\section{c. Pendampingan Masyarakat Sipil}

KOPEL melakukan kerja-kerja advokasi masyarakat sipil. Kerja advokasi ini dilakukan mengingat banyaknya permasalahan kebijakan pemerintah daerah yang bersentuhan langsung dengan masyarakat sipil. Permasalahan lemahnya elemen masyarakat sipil membawa KOPEL pada suatu upaya pengorganisasian dan pendampingan masyarakat sipil. Sebagai bagian dari aktor atau pelaku perubahan (agent of change), pengorganisasian masyarakat secara terstruktur dan sistematis menjadi sesuatu yang 
mendesak untuk menjawab gejala melemahnya posisi warga dalam pengambilan keputusan publik. Dalam mengorganisir masyarakat sebagai kelompok dampingan, KOPEL selama ini secara khusus menggunakan istilah Parlemen Group.

Istilah Parlemen Group pertama kali digunakan oleh KOPEL Sulawesi pada tahun 2001 untuk penyebutan kelompok dampingan yang dibentuk di sejumlah daerah di Sulawesi Selatan. Parlemen Group adalah wadah berkumpul dan berjuangnya sekelompok masyarakat sipil - termasuk masyarakat petani dan nelayan, kelompok perempuan dan kelompok masyarakat kurang beruntung (Denny, 2006). Bagi KOPEL, penggunaan istilah parlemen grup bagi masyarakat dampingan diterjemahkan sebagai bagian dari strategi atau ideologi gerakan yang sebenarnya berkeinginan menarik relasi dan komunikasi politik yang kuat dari lembaga parlemen dengan masyarakat sipil atau konstituennya. Begitu pula sebaliknya, untuk mendorong masyarakat sipil agar lebih peduli dan aktif membangun komunikasi sekaligus kontrol terhadap wakilnya di parlemen. Program-program penguatan masyarakat lewat Parlemen Group semangatnya adalah bagaimana menerjemahkan parlemen baik secara institusional maupun sebagai individu pemegang mandat rakyat yang seharusnya lebih dekat dengan suara batin dan emosional masyarakatnya (Putra, 2018). Dalam artian komunikasi politik antara masyarakat sebagai pihak yang diwakili dengan anggota parlemen sebagai pihak yang diwakili. Untuk komunikasi tersebut, KOPEL berperan sebagai intermediary antara keduanya. Untuk mendorong komunikasi antara masyarakat sipil dengan anggota DPRD, KOPEL memanfaatkan media sebagai bagian dari sasaran advokasi masyarakat sipil. Disamping sebagai target group, media juga dijadikan sebagai alat untuk membangun opini publik terhadap setiap kebijakan yang dibuat oleh pemerintah daerah, melakukan desiminasi informasi terkait dengan kerja-kerja advokasi lembaga. Kampanye dan publikasi dilakukan melalui pers conferences dengan melibatkan media cetak, elektronik dan media-media alternatif lainnya berupa pamflet, brosur, stiker, baliho, pemutaran film, talkshow.

KOPEL juga banyak memanfaatkan kerja sama yang telah terbangun selama ini dengan media baik sebagai narasumber berita, terlibat dalam program di media bersangkutan dan pola-pola keterlibatan KOPEL lainnya dalam mensuplai data dan berita untuk kepentingan pemberitaan media.

\section{Tingkat Keberhasilan Komite Pemantau Legislatif (Kopel) Dalam Mendorong Kinerja Legislasi Dprd Kota Makassar}

\section{a. Peningkatan pemahaman dalam menyusun peraturan}

Hal ini mendorong peningkatan skill/kemampuan anggota DPRD dalam merumuskan atau menyusun peraturan sebagaimana fungsi legislasinya di dewan. Mengingat bahwa latar belakang pendidikan anggota dewan yang berbeda-beda hadirnya kagiatan-kegiatan yang dilakukan oleh KOPEL menunjang kinerja dan pemahaman anggota DPRD Kota Makassar dalam menyusunan sebuah program peraturan.

\section{b. Peningkatan transparansi kapasitas kinerja sekretariat DPRD Kota Makassar}

Sekretariat DPRD Kota Makassar harus disusun sebagai pendukung untuk meningkatkan kualitas, produktivitas, dan kinerja pelaksanaan fungsi dan tugas DPRD kota Makassar. Peran dan tanggungjawab sekretariat DPRD menjadi semakin penting dan dominan, ketika adanya tuntutan yang didasari pemikiran bahwa sistem pemerintahan daerah menempatkan lembaga legislatif pada posisi yang sejajar dengan eksekutif yang dipimpin oleh bapati/walikota. Sekretariat DPRD kab/kota dibentuk untuk mendukung 
pelaksanaan fungsi dan tugas pokok DPRD kabupaten/kota dalam rangka meningkatkan kualitas, produktivitas, dan kinerja lembaga perwakilan rakyat daerah.

\section{c. Memperkuat transparansi dukungan penerimaan aspirasi masyarakat dan pengawasan pemerintahan}

Aspirasi yang dibawa langsung oleh masyarakat untuk disampaikan kepada wakilwakilnya di DPRD merupakan fenomena baru dalam hal menyampaikan pendapat diera reformasi ini. aspirasi demikian pada hakikatnya adalah kebutuhan masyarakat untuk memperoleh kejelasan informasi yang solutif dan problematika-problematika yang dihadapi langsung oleh masyarakat. Anggota DPRD kota Makassar adalah bagian terpenting dari masyarakat sebagai wakil rakyat yang membawa aspirasi secara melembaga. Dengan demikian penerimaan aspirasi menjadi tugas yang melekat sebagai anggota DPRD. Aspirasi yang diterima DPRD kota Makassar menjadi acuan dalam pelaksanaan tugas pengawasan DPRD terhadap penyelenggaraan pemerintah daerah. Aspirasi yang ditindak lanjuti oleh DPRD adalah melalui hearing dengan stakeholder, sebagai bahan acuan bagi anggota DPRD ketika mengadakan reses.

KOPEL hadir sebagai sebagai jembatan aspirasi antara masyarakat dan anggota DPRD. Melakukan hearing bersama anggota DPRD atau rapat dengar pendapat yang dilakukan, baik membahas rancangan peraturan daerah dengan kopel menghadirkan draft analisis untuk disampaikan kepada DPRD untuk ditindaklanjuti dalam rapat pembahasan peraturan dalam sidang pembahasan bersama anggota DPRD.

\section{d. Memperkuat transparansi dengaan fasilitas e-parliament Kopel Sulawesi}

Hadirnya LSM KOPEL serta kemajuan teknologi informasi sangat bermanfaat bagi pelaksanaan tugas-tugas dewan perwakilan rakyat daerah E-Parliament (electronic parliament) menjadi bagian yang tidak terpisahkan dari transparansi informasi yang dilakukan oleh DPRD Kota Makassar. E-parliament sangat efektif untuk membangun komunikasi antara anggota dewan dan konstituen, anggota dewan dan aparat pemerintah daerah serta anggota DPRD dengan staf sekretariat.

DPRD kota Makassar telah melakukan kerjasama dalam jaringan internet website KOPEL sebagai dukungan terhadap pelaksanaan tugas DPRD Kota Makassar. KOPEL sebagai NGO (Non Government Organization) mendorong dan memfasilitasi DPRD Kota Makassar dalam pemanfaatan E-Parliament. Oleh karena itu, aktifitas-aktifitas DPRD diakses dalam www kopel-online.com. dane-mail kopelmakassar@yahoo.com.

Masyarakat dapat mengakses aktifitas-aktifitas DPRD melalui website KOPEL tersebut untuk memperoleh dokumen-dokumen dan hasil-hasil keputusan DPRD Kota Makassar. Bahwa dengan hadirnya E-Parliament kopel Sulawesi juga memacu sekretariat DPRD kota Makassar untuk memprioritaskan memasang kembali jaringan internet untuk mendukung tugas dan sekaligus sebagai media sosialisasi produk-produk DPRD kota Makassar berupa dokumen-dokumen publik yang seharusnya diketahui oleh masyarakat umum dan agenda DPRD Kota Makassar.

\section{e. Membangun keahlian legal drafting}

Dukungan keahlian untuk membantu anggota dewan mengenai materi atau substansi peraturan. Oleh sebab itu, keahlian yang harus dimiliki oleh anggota DPRD adalah ahli dalam bidang perancangan peraturan-peraturan. KOPEL hadir memberikan pelatihan legal drafting untuk melibatkan individu anggota DPRD bukan lembaga DPRD, sebab yang diberikan wewenang dalam pelatihan yang melibatkan lembaga adalah 
Jumal Sosiafisasi

Jurnal Hasil Pemikiran, Penelitian, dan Pengembangan

Keilmuan Sosiologi Pendidiikan

Vol 8, Nomor 1, Maret 2021

kementerian dalam negeri (Kemendagri) dan perguruan tinggi. Produk peraturan daerah yang dikeluarkan oleh DPRD Kota Makassar masih banyak mengalami kekurangan disebabkan minimnya analisis dalam mengeluarkan sebuah produk peraturan. KOPEL selalu memantau kinerja legislasi DPRD Kota Makassar dalam menyusun peraturan daerah yang dikeluarkan. Peran strategis KOPEL adalah hearing bersama anggota DPRD sebelum membahas peraturan agar produk peraturan yang dikeluarkan tidak terkesan memonopoli dan tidak bertentangan dengan peraturan yang lebih tinggi.

\section{PENUTUP}

Berdasarkan hasil penelitian tentang Peran Komite Pemantau Legislatif (KOPEL)

Dalam Mendorong Kinerja Legislasi DPRD Kota Makassar maka dapat di tarik kesimpulan sebagai berikut:

1. Peran Komite Pemantau Legislatif (KOPEL) dalam mendorong kinerja legislasi DPRD Kota Makassar dilakukan pada dasarnya memiliki tujuan yang sangat baik menunjang peningkatan kinerja legislasi DPRD Kota Makassar. Tetapi, dalam realitas pelaksanaannya program kerjanya belum cukup maksimal dengan melihat beberapa program kerja dan agenda yang dilakukan belum memenuhi indikator keberhasilan. Disebabkan kurang antusiasnya anggota DPRD Kota Makassar untuk terlibat dalam kegiatan peningkatan pemahaman dalam menyusun peraturan. Tetapi dari sisi progress kinerja DPRD Kota Makassar telah mengalami sedikit kemajuan dari sebelumnya bisa dilihat dari tingkat keberhasilan KOPEL dan tidak lepas dari hal yang dilakukan oleh KOPEL.

2. Tingkat keberhasilan Komite Pemantau Legislatif (KOPEL) dalam mendorong kinerja legislasi DPRD Kota Makassar lebih fokus pada peningkatan transparansi dan skill/kemampuan Peningkatan pemahaman anggota DPRD dalam menyusun peraturan. Dapat kita simpulkan dari hasil penelitian ini bahwa kegiatan yang dilakukan oleh KOPEL dalam mendorong meningkatkan kinerja legislasi DPRD kota Makassar belum berjalan dengan maksimal. Sebab masih diperhadapkan dengan faktor penghambat dilapangan.

Masyarakat Kota Makassar khususnya perlu terus mengevaluasi kinerja DPRD Kota Makassar melalui KOPEL sebab selaku wakil rakyat perlu kiranya untuk benar-benar menyampaikan aspirasi rakyat kepada pemerintah. Agar tidak di eksploitasi kepentingankepentingan kelompok tertentu pada Dewan Perwakilan Rakyat.

\section{DAFTAR PUSTAKA}

Buchari, S. A. (2014). Kebangkitan etnis menuju politik identitas. Yayasan Pustaka Obor Indonesia.

Danusastro, S. (2016). Penyusunan Program Legislasi Daerah yang Partisipatif. Jurnal Konstitusi, 9(4), 643-660.

Denny, J. A. (2006). Membaca isu politik. PT LKiS Pelangi Aksara.

Firdaus, M. (n.d.). Pengawasan Pemerintah terhadap Penyalahgunaan Lembaga Swadaya Masyarakat (LSM). Fakultas Syariah dan Hukum Universitas Islam Negeri Syarif Hidayatullah Jakarta.

Haris, S. (2005). Desentralisasi dan otonomi daerah: desentralisasi, demokratisasi \& akuntabilitas pemerintahan daerah. Yayasan Obor Indonesia.

Kartini, D. S. (2017). Demokrasi dan Pengawas Pemilu. Journal of Governance, 2(2).

Kusuma, T. C. (2019). Konsep Ideal Pengawasan Terhadap Keuangan Daerah Untuk 
Jumal Sosiafisasi

Jurnal Hasil Pemikiran, Penelitian, dan Pengembangan Keilmuan Sosiologi Pendidikan

Vol 8, Nomor 1, Maret 2021

Mewujudkan Tata Kelola Pemerintahan Yang Baik Berbasis Keadilan. Universitas Islam Sultan Agung.

Maksum, R. A. (2020). Peran organisasi kepemudaan Gambleng dalam pembangunan masyarakat Desa Banmaleng Kecamatan Giligenting Kabupaten Sumenep. UIN Sunan Ampel Surabaya.

Permana, B. N. (2018). Konflik Dalam Kebijakan Reklamasi Teluk Utara Jakarta Pada Masa Pemerintahan Basuki Tjahaja Purnama (Ahok) Periode (2015-2017). Jakarta: Fakultas Ilmu Sosial Dan Ilmu Politik UIN Syarif Hidayatullah.

Putra, D. K. S. (2018). Political social responsibility: Dinamika komunikasi politik dialogis. Prenada Media.

Rahmanurrasjid, A. (2008). Akuntabilitas dan transparansi dalam pertanggungjawaban pemerintah daerah Untuk mewujudkan pemerintahan yang baik di daerah (Studi di Kabupaten Kebumen). Program Pascasarjana Universitas Diponegoro.

Setiadi, E. M., \& Kolip, U. (2013). Pengantar sosiologi politik. Kencana.

Suharto, E. (2005). Membangun Masyarakat Memberdayakan Rakyat Kajian Strategis Pembangunan Kesejahteraan Sosial dan Pekerjaan Sosial. PT Refika Aditama.

Tiran, R. P. (2016). Pelaksanaan Tugas dan Wewenang Panitia Pengawas Pemilihan (Panwas) Kabupaten Bantul dalam Penyelenggaraan Pemilihan Bupati dan Wakil Bupati Kabupaten Bantul Tahun 2015. UII Yogyakarta.

Tutik, T. T., \& SH, M. H. (2016). konstruksi hukum tata negara Indonesia pasca amandemen UUD 1945. Prenada Media.

Ulhaq, D. (2021). Penggunaan Hak Interpelasi DPRA terhadap Kebijakan Pemerintah Aceh di Era Pandemi. UIN Ar-Raniry. 